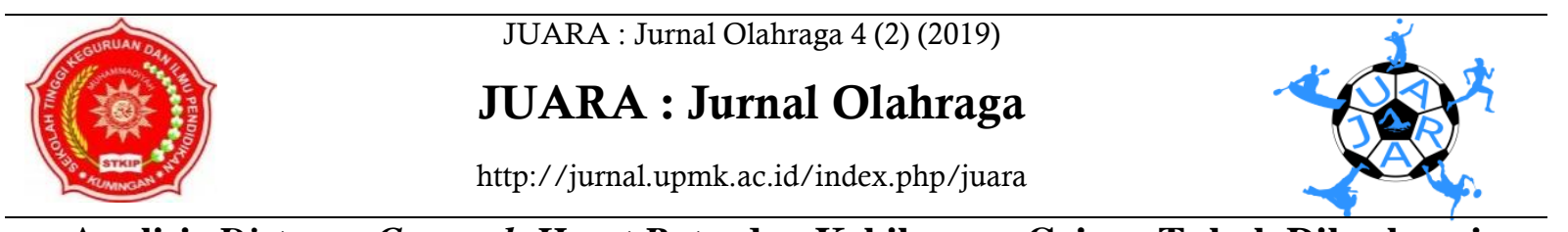

Analisis Distance Covered, Heart Rate, dan Kehilangan Cairan Tubuh Diberbagai Posisi Pada Pemain Sepakbola

\title{
The Annalysis of Distance Covered, Heart Rate, and Body Fluid Loss in Every Position of Football Player
}

\author{
Muhammad Yusuf Rojali Rahmatillah ${ }^{1)}$, Eka Nugraha ${ }^{2)}$, Hamidie Ronald Daniel Ray ${ }^{3)}$ \\ ${ }^{1}$ Postgraduate in Physical Education, Universitas Pendidikan Indonesia, Jl. DR. Setiabudi No.229, Isola, \\ Kec. Sukasari, Kota Bandung, Jawa Barat 40154, Indonesia \\ ${ }^{2,3}$ Faculty of Physical Education and Health, Universitas Pendidikan Indonesia, Jl. DR. Setiabudi \\ No.229, Isola, Kec. Sukasari, Kota Bandung, Jawa Barat 40154, Indonesia \\ email: Yusufrojali@ student.upi.edu ${ }^{1}, \underline{\text { ekafok@upi.edu }}{ }^{2}, \underline{\text { hamidieronald @ upi.edu }}^{3}$ \\ do https://doi.org/10.33222/juara.v4i2.615
}

\section{Info Artikel}

Sejarah Artikel:

Diterima 22 Juni 2019

Disetujui 22 Juli 2019

Dipublikasikan 24 Juli 2019

Keywords:

Distance Covered, heart rate, kehilangan cairan tubuh, pemain sepakbola

\section{Abstrak}

Tujuan penelitian untuk menganalisis sampai sejauh mana jarak tempuh (distance covered), heart rate, dan kehilangan cairan tubuh diberbagai posisi pada pemain sepakbola profesional Indonesia, sebagai bahan dasar untuk merencanakan suatu program latihan Metode penelitian ini menggunakan metode deskriftif kuantitatif. Sampel penelitian ini yaitu tim 11 pemain BUFC dalam pertandingan Piala Presiden 2019 melawan SPFC dengan menggunakan pendekatan teknik purposive sampling. Hasil dari penelitian ini menunjukan jarak tempuh (distance covered) paling jauh dicapai External Midfielder 10.421 m, Heart Rate Maximum paling tinggi dicapai Central Midfield 200 bpm, Average heart rate paling tinggi External Defender 165 bpm, kehilangan cairan tubuh paling besar Central Midfielder 0,9\%. Kesimpulan peneitian berdasarkan dari hasil analisis data menunjukan bahwa Central Midfielder, External Midfielder, dan External Defender merupakan posisi yang paling banyak melakukan jarak tempuh (Distance Covered), heart rate maximum paling tinggi, average heart rate paling tinggi, dan kehilangan cairan tubuh paling banyak.

\footnotetext{
Abstract

The aim of this study was to analyze the extent of distance, heart rate, and loss of body fluids in various positions in Indonesian professional soccer players as the basic material for planning an exercise program Method: this study uses a quantitative descriptive method. The sample of this study is the 11-player BUFC team in the 2019 Presidential Cup match against SPFC using a purposive sampling technique approach. The results of this study show the distance covered the most reached External Midfielder $10.421 \mathrm{~m}$, the highest Heart Rate Maximum reached Central Midfielder 200 bpm, Average heart highest rate External Defender 165 bpm, the biggest loss of body fluids Central Midfielder $0.9 \%$. The conclusion of the research based on the results of data analysis shows that Central Midfielder, External Midfielder, and External Defender are the positions that do the most distance (Distance Covered), maximum maximum heart rate, highest average heart rate, and the most loss of body fluids.
} 


\section{(C) 2019 Muhammad Yusuf Rojali Rahmatillah, Eka Nugraha, Hamidie Ronald Daniel Ray \\ Under the license CC BY-SA 4.0}

\footnotetext{
$\bowtie$ Alamat korespondensi: Jl. DR. Setiabudi No.229, Kota Bandung

E-mail_:yusufrojali@student.upi.edu

No Handphone :085723783605
}

\section{PENDAHULUAN}

Sepakbola ditandai dengan permainan yang dimainkan oleh 2 tim dan masing-masing tim 11 orang pemain orang pemain tentunya memiliki posisi berbeda-beda. Pada umumnya posisi pemain sepakbola terdiri dari: Penjaga gawang, bek, gelandang, dan penyerang (Taylor, Hencken, White, Hencken, \& White, 2006). Posisi pemain ini dikembangkan kepada beberapa posisi yaitu goal keeper (GK) central defenders (CD), external defenders (ED), central midfield players (CM), external midfield players (EM) and forwards (F) (Di Salvo et al., 2007) tentunya memiliki fungi dan tugas masing-masing.
ISSN 2655-1896 (online)

ISSN 2443-1117 (cetak)

Dalam pertandingan sepakbola, rata-rata setiap pemain membutuhkan jarak sekitar 9-14 $\mathrm{km}$ untuk jarak tempuh (distance covered) (Russell et al., 2016). Selama Piala Dunia 2010 di Afrika Selatan, jarak terbesar dalam pertandingan yang dianalisis dicakup oleh gelandang tengah (dari 12,3 ke 12,9 km), Forward (dari 10,5 ke 11,9 km) dan pemain bertahan (dari 10,8 hingga 12,0 km) (Bojkowski, Eider, Śliwowski, \& Wieczorek, 2015). Hal ini menunjukan karakter permainan sepakbola yang memaksakan kinerja fisik pemain elite didasarkan pada kombinasi daya tahan, kecepatan, kelincahan dan kekuatan selama pertandingan sepakbola berlangsung (Boone, Vaeyens, Steyaert, Bossche, \& Bourgois, 2012).

Table 1. Distance Covered Pemain Liga Eropa

\begin{tabular}{cc}
\hline \multicolumn{2}{c}{ Distance Covered } \\
\hline Posisi & Jarak tempuh \\
Central Defender & 10336 \\
External Defender & 11063 \\
Central Midfielders & 11760 \\
External Midfielders & 11746 \\
Forwards & 10940 \\
\hline
\end{tabular}

Selanjutnya, selama 10 pertandingan yang ada di Liga Eropa musim 2008-2009 dan 2010/2011 menunjukan hasil bahwa pemain CD (Central Defender) menempuh jarak sejauh $10.3 \mathrm{~km}$, ED (External Defender) menempuh jarak sejauh $11.1 \mathrm{~km}, \mathrm{CM}$ (Central Midfielders) menempuh jarak sejauh $11.8 \mathrm{~km}$, EM (External Midfielders) menempuh jarak sejauh $11.7 \mathrm{~km}$, dan F (Forwards) menempuh jarak sejauh $11.2 \mathrm{~km}$ (Andrzejewski, Chmura, Pluta, \& Konarski, 2015).

Sepakbola merupakan olahraga yang bersifat dominan aerobik, akan tetapi didalamnya terdapat gerakan-gerakan anaerobik, seperti: perpaduan sprint dengan jarak pendek dengan waktu yang singkat, lari dengan intensitas tinggi (HIR), lompatan, duel heading, tackles, perubahan arah, mundur, dengan rata-rata intensitas permainan berkisar antara 80 sampai $90 \%$ detak jantung maksimal (HRmax). Pengukuran mengenai Heart Rate telah dilakukan sejak akhir tahun 1960an. Hal ini bertujuan untuk memeriksa beban fisiologis selama pertandingan dan latihan sepakbola (Alexandre et al., 2012). Pada penelitian sebelumnya mengungkapkan bahwa rata-rata 
Heart Rate pemain sepakbola remaja melebihi $170 \mathrm{kali} / \mathrm{menit}$ untuk $84 \%$ dari total durasi pertandingan selama pertandingan resmi dengan lapangan reguler $\left(\begin{array}{lllll}100 & \mathrm{x} & 65 & \mathrm{~m}\end{array}\right)$ (Capranica, Tessitore, Guidetti, \& Figura, 2010). Selama pertandingan analisis capaian heart rate paling tinggi di capai Midfielder sebesar 176 bpm, kemudian Forward 173 bpm, dan Defender 166 bpm (Ali \& Farrally, 2007). Penelitian ini hanya meneliti mengenai Heart Rate dari keseluruhan secara umum pemain dan pada kenyataannya perlu diteliti Heart Rate tiap pemain dari berbagai posisi karena hasilnya bisa digunakan sebagai bahan pertimbangan bagi pelatih untuk merancang program yang lebih spesifik setiap pemain.

Dalam pertandingan sepakbola variable intensitas keseluruhan sebesar 70-80\% dari VO2Max, dan tergantung kepada posisi bermain (Bangsbo, Mohr, Krustrup, \& Bangsbo, 2006). Intensitas dalam permainan sepakbola akan meningkatkan suhu inti tubuh dan direspon dengan keringat keluar, hal ini menyebabkan kehilangan cairan dalam tubuh (Phillips, et al 2014). Kehilangan cairan yang terus menerus sebagai bagian dari total body water (TBW) dapat menyebabkan penurunan secara progresif pada tekanan paru secara sistemik, peningkatan suhu inti, penurunan aliran darah kulit, dan penurunan keseluruhan dalam cardiac output ketika volume stroke menurun di luar kompensasi peningkatan denyut jantung (HR) (Siegler et al., 2008).

Kehilangan cairan tubuh atau dehidrasi sebanyak 1-2 \% dari berat badan dapat mempengaruhi fungsi fisiologis tubuh (homeostasis) dan berdampak negatif terhadap prestasi atlet. Kehilangan cairan tubuh lebih dari $3 \%$ berat badan dapat meningkatkan resiko terjadinya kram, keletihan yang parah, dan heat stroke (Siregar, 2016).

Dari beberapa penelitian hanya mengungkapkan hasil yang dicapai pemain selama pertandingan. Untuk dapat mencapai kinerja puncaknya maka diperlukan pemahaman dan aplikasi dari prinsip-prinsip dari sebuah periodisasi sebagai bahan penataan proses latihan dan partisipasi kompetisi ke dalam berbagai fase, periode dan siklus (Lyakh, et.al 2016). Dalam pencapaian prestasi maksimal seorang atlet maka dibutuhkan suatu perencanaan program latihan yang dirancang berdasarkan hasil tes atau kebutuhan pemain pada saat pertandingan. Dengan adanya data berupa jarak tempuh (Distance Covered), Heart Rate, dan kehilangan cairan tubuh akan membatu pelatih sebagai data awal dalam menentukan program latihan agar pemain dapat mencapai peak performance pada waktu yang sudah ditentukan. Perolehan hasil data yang di dapat akan menentukan garis volume dan intensitas pada saat merancang program latihan sesuai dengan karakteristik setiap pemain.

Perolehan data mengenai jarak tempuh (Distance Covered) dapat membatu perencanaan program latihan dalam menentukan garis volume latihan bagi individu pemain. Sedangakan Heart Rate menggambarkan intensitas gerak pemain selama pertandingan, hal ini menjadikan acuan bagi pelatih dalam melaksanakan program latihan yang nantinya akan berdampak pada pemantauan training zone inidividu pemain. Sadar dengan aktivitas dalam permainan sepakbola yang memerlukan tingkat kinerja tinggi dipantau dengan data jarak tempuh (Distance Covered) dan Heart Rate, sehingga mempengaruhi fungsi fisiologis dalam tubuh terutama bayaknya cairan yang keluar berupa keringat. Oleh karenanya kebutuhan pemain dalam asupan cairan pada saat pertandingan maupun latihan sangat diperlukan mengingat permainan sepakbola dimainkan dengan durasi 90 menit maka diperlukan asupan cairan yang bagus bertujuan untuk tetap mengontrol homeostasis tubuh pada saat pertandingan.

Belum adanya peneitian yang membahas mengenai jarak tempuh (distance covered), Heart Rate dan kehilangan cairan tubuh di Indonesia, maka dari itu tujuan dari penelitian ini untuk menganalisis jarak tempuh 
(distance covered), Heart Rate dan kehilangan cairan tubuh selama pertandingan di berbagai posisi pemain sepakbola professional di liga Indonesia yang nantinya dijadikan sebagai bahan acuan perecanaan periodisasi latihan berdasarkan prinsip individualisasi dan spesifikasi sesuai kebutuhan setiap pemain.

Maka dari itu, pada penelitian ini ditujukan untuk menjawab beberapa pertanyaan yaitu: Sampai sejauh mana jarak tempuh (distance covered) pemain sepakbola professional Indonesia di berbagai posisi? Sampai sejauh mana rata-rata Heart Rate pemain sepakbola professional Indonesia di berbagai posisi? Sampai sejauh mana kehilangan cairan pemain sepakbola professional Indonesia di berbagai posisi?

\section{METODE PENELITIAN}

Metode penelitian dalam penelitian yang digunakan dalam penelitian ini yaitu dengan menggunakan metode deskriftif kuantitatif dengan jenis penelitian komparasi. Dengan demikian, penelitian deskriftif dengan jenis komparasi ini bertujuan untuk mengungkapkan data yang ada dilapangan dan kemudian dibandingkan sesuai keadaan. Dalam konteks penelitian ini peneliti akan mengungkapkan data mengenai jarak tempuh (distance covered), heart rate, kehilangan cairan tubuh diberbagai posisi pemain sepakbola dan kemudian data tersebut dibandingkan dengan data yang sudah ada berdasarkan penelitian terdahulu sebagai bahan pembanding dan evaluasi tim pelatih.

Populasi dalam penelitian ini adalah seluruh pemain Bali United yang berjumlah 30 pemain BUFC, Teknik sampling pada penelitian ini menggunakan purposive sampling dengan mempertimbangkan dalam mengambil sampel untuk diteliti. Maka dari itu, sampel yang penulis ambil dari penelitian ini adalah sebanyak 11 orang pemain yang merupakan kerangka pemain inti dalam tim.

Dalam penelitian ini, instrumen yang digunakan untuk mengukur jarak tempuh, heart rate dan kehilangan cairan tubuh yaitu: Video Kamera, Polar Team 2 Pro dan GPSport, dan Timbangan Digital.

Langkah pertama dalam penelitian ini yaitu menentukan populasi penelitian, kemudian akan memilih sampel yang akan digunakan. Pada langkah ketiga yaitu melakukan tes berat badan sebelum pertandingan, kemudian para pemain akan dipasang polar untuk mengetahui hasil penelitian sesuai yang akan diteliti, para pemain akan bermain sepakbola selama $2 \times 45$ menit sesuai waktu pertandingan sepakbola.

Data yang diperoleh dari hasil tes merupakan data mentah, sehingga perlu pengolahan data. Data yang sudah dikumpulkan kemudian dianalisis secara kuantitatif melalui perhitungan statistik dengan langkah sebagai berikut : Deskripsi data, rata-rata, nilat terbesar, dan nilai terkecil.

\section{HASIL DAN PEMBAHASAN}

Data yang diperoleh dari hasil penelitian merupakan skor-skor mentah, selanjutnya data tersebut diolah secara persentase agar skorskor tersebut dapat dianalisis dan dapat disimpulkan dengan menggunakan descriptive data.

Grafik 1 menunjukan perolehan data mengenai jarak tempuh (distance covered) pemain BUFC pada pertandingan Piala Presiden 2019 melawan SPFC. Data tersebut dapat dilihat bahwa External Midfielder menempuh jarak paling jauh yaitu $10.421 \mathrm{~m}$ sedangkan jarak yang paling dekat yaitu Central Defender dengan jarak 8.656 m. Hasil dari data diatas memilliki perbedaan disetiap posisi yang tergantung pada gaya bermain tim BUFC dan kinerja pemain. 
Grafik 1. Distance Covered

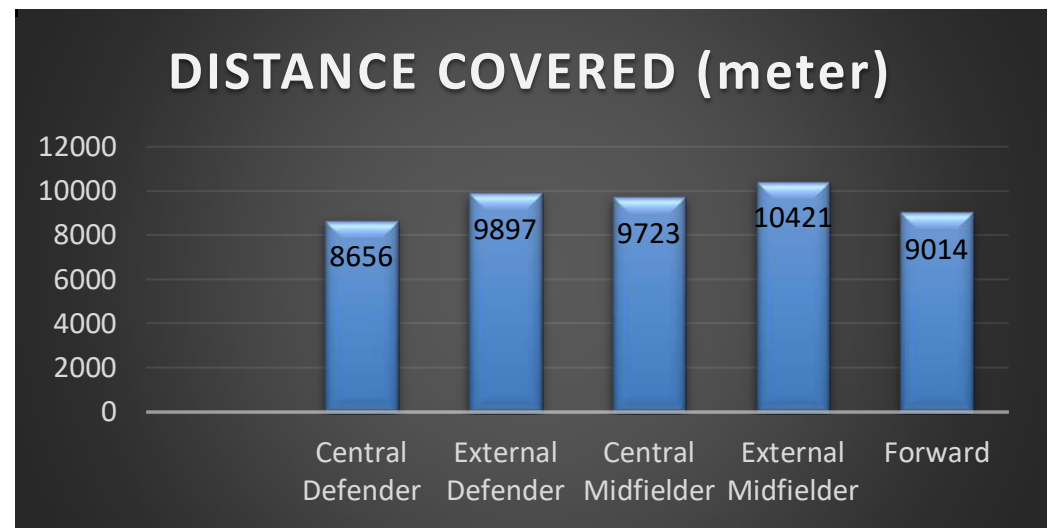

Grafik 2 menjelaskan mengenai perbandingan jarak tempuh (Distance Covered) disetiap posisi pemain BUFC pada pertandingan Piala Presiden 2019 melawan SPFC dengan hasil dari 10 pertandingan yang ada di Liga Eropa musim 2008-2009 dan
2010/2011 (Andrzejewski et al., 2015). Seperti diketahui bahwa jarak paling jauh di tempuh oleh Central Midfielder $(11.760,4 \quad \mathrm{~m})$, kemudian sedikit jarak tempuh yaitu Central Defender berjarak (10.355,9 m).

Grafik 2. Perbandingan Distance Covered

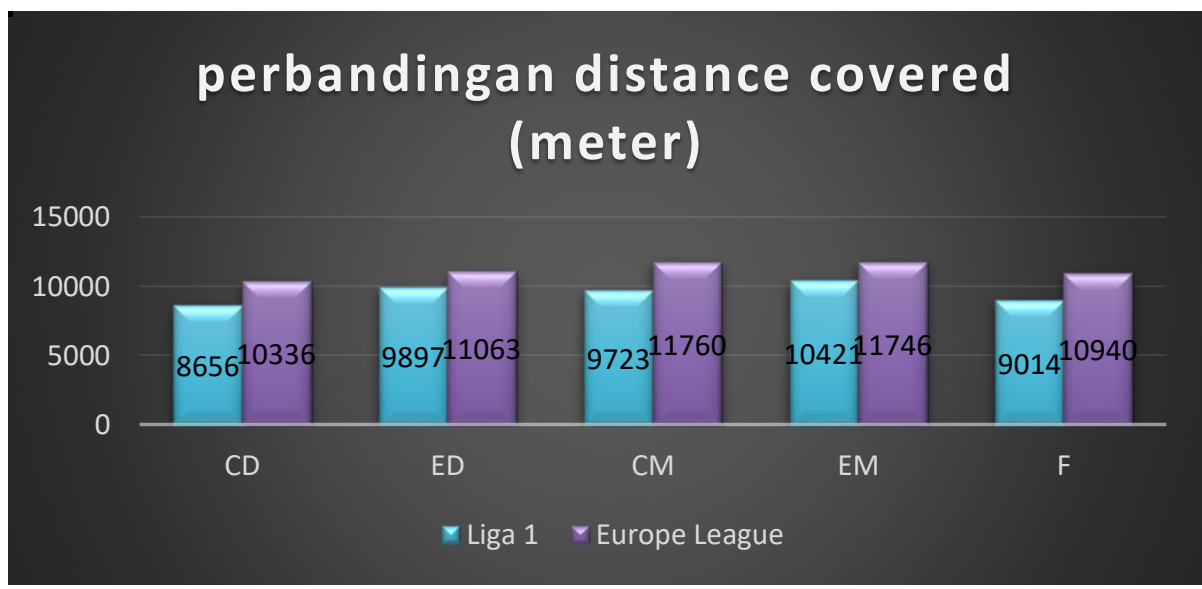

Pada penelitian sebelumnya dijelaskan bahwa pemain Central Midfielder menempuh jarak paling jauh dibandingkan dengan posisi yang lain. Namun, berbeda dengan hasil yang diperoleh dari pertandingan yang ada di liga Indonesia bahwa pemain BUFC yang paling jauh jarak tempuh di capai pemain External Midfielder. Oleh karena belum adanya penelitian mengenai pembahasan jarak tempuh (Distance Covered) pemain disetiap posisi di indonesia, maka hal ini menjadikan sebuah penemuan baru dalam penelitian bahwa jarak tempuh (Distance Covered) pemain BUFC lebih didominasi oleh pemain External
Midfielder. Sedangkan pada penelitian sebelumya dijelaskan bahwa jarak tempuh (Distance Covered) pemain paling jauh ditempuh Central Midfielder.

Jika dilihat dari hasil jarak tempuh pemain Liga Eropa dengan Indonesia menunjukan bahwa ada 3 posisi bermain yang hampir memiliki peran yang sangat dominan yaitu: Central Midfielder, External Midfielder, dan External Defender. Ketiga posisi ini merupakan posisi yang paling banyak melakukan aktivitas dalam pertandingan terutama jarak tempuh (Distance Covered). Sedangkan seorang Central Defender 
memiliki jarak tempuh (Distance Covered) paling sedikit baik di Liga eropa maupun Liga Indonesia. Dengan demikian hasil ini memberikan gambaran bahwa ada sisi penguat dari penelitian sebelumnya mengenai capaian jarak tempuh paling jauh di dominasi oleh pemain Central Midfielder, External Midfielder, dan External Defender baik di liga Indonesia maupun liga Eropa.

Data diatas sangat penting bagi para pemain Indonesia sebagai bahan perbandingan jarak tempuh (Distance Covered) pemain professional Liga Eropa dan pemain Liga Indonesia. Akan tetapi, pada data ini hanya sebagai pembanding saja untuk bahan evaluasi tim pelatih dalam menerapkan program latihan. Selanjutnya, data Distance Covered yang diperoleh menjadikan acuan awal dalam menentukan program latihan yang sesuai dengan kebutuhan pemain disetiap posisi berdasarkan kepada prinsip-prinsip latihan yaitu prinsip specificity dan individualisasi.

Grafik 3. Heart Rate Monitor

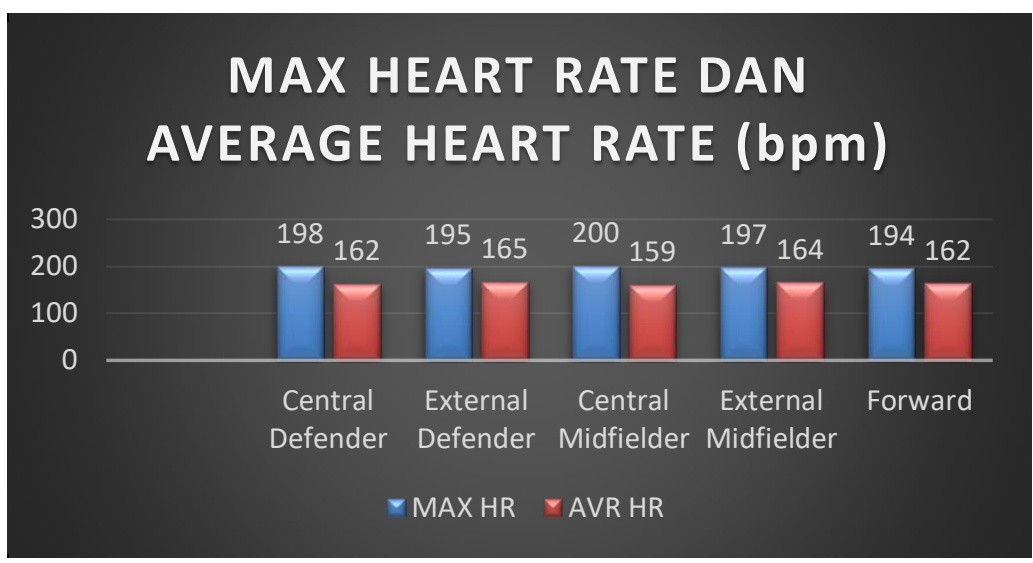

Grafik 3 menjelaskan mengenai monitor Heart Rate Maximum dan Average Heart Rate pemain BUFC pada pertandingan Piala Presiden 2019 melawan SPFC. Berdasarkan data diatas Heart Rate Maximum paling tinggi dicapai Central Midfielder 200 bpm kemudian paling rendah ada di posisi Forward 194 bpm. Sedangkan untuk pencapaian paling tinggi average heart rate pemain selama pertandingan dicapai oleh External Defender 165 bpm, kemudian hasil paling rendah Central Midfielder 159 bpm.

Hasil diatas memiliki persamaan dan perbedaan di berbagai posisi, hal ini menunjuka kinerja pemain selama pertandingan.

Grafik 4. Data Pengukuran Berat Badan Sebelum dan Sesudah Pertandingan

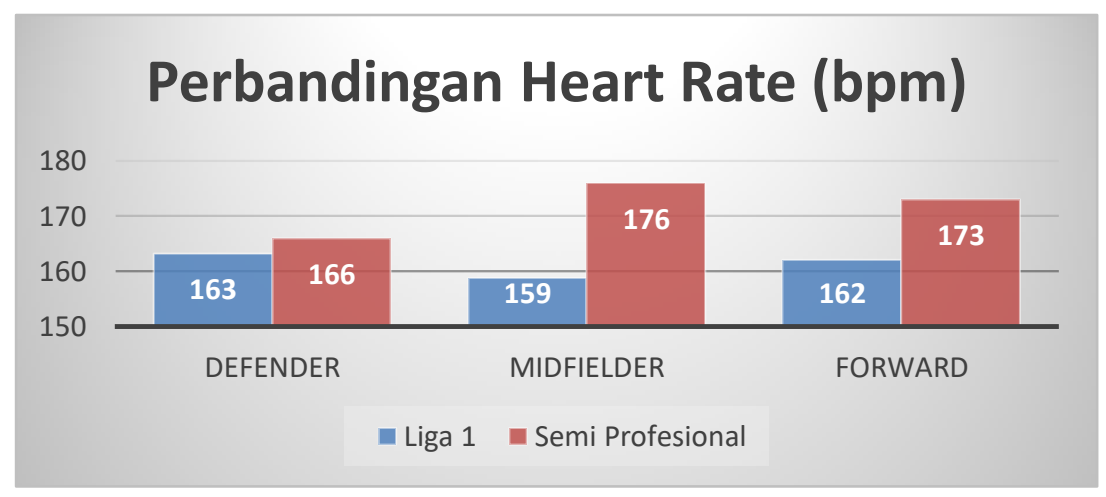


Data pada grafik 4 di atas merupakan perbandingan Average Heart Rate pemain BUFC dengan pemain semi profesional (Ali \& Farrally, 2007). Seperti yang diketahui bahwa Heart Rate paling besar dicapai oleh pemain Midfielder sebesar 176 bpm, kemudian Forward 173 bpm, dan Defender 166 bpm. Dari data diatas terdapat perbedaan pencapaian tertinggi Heart Rate antara pemain BUFC dengan pemain semi profesional, capaian tertinggi dari BUFC dicapai oleh pemain Defender sedangkan pada pemain semi profesioal dicapai pemain Midfielder, nilai paling kecil dari BUFC United dicapai pemain Midfielder sedangkan dari pemain semi profesional dicapai Defender.

Berdasarkan data pada grafik 4 menjelaskan terdapat temuan baru mengenai capaian Heart Rate pemain sepakbola diberbagai posisi. Data penelitian sebelumnya mengemukakan bahwa capaian tertinggi Heart Rate pemain selama pertandingan dicapai pemain Midfieder sedangkan BUFC dicapai oleh pemain defender.

Grafik 5. Data Pengukuran Berat Badan Sebelum dan Sesudah Pertandingan

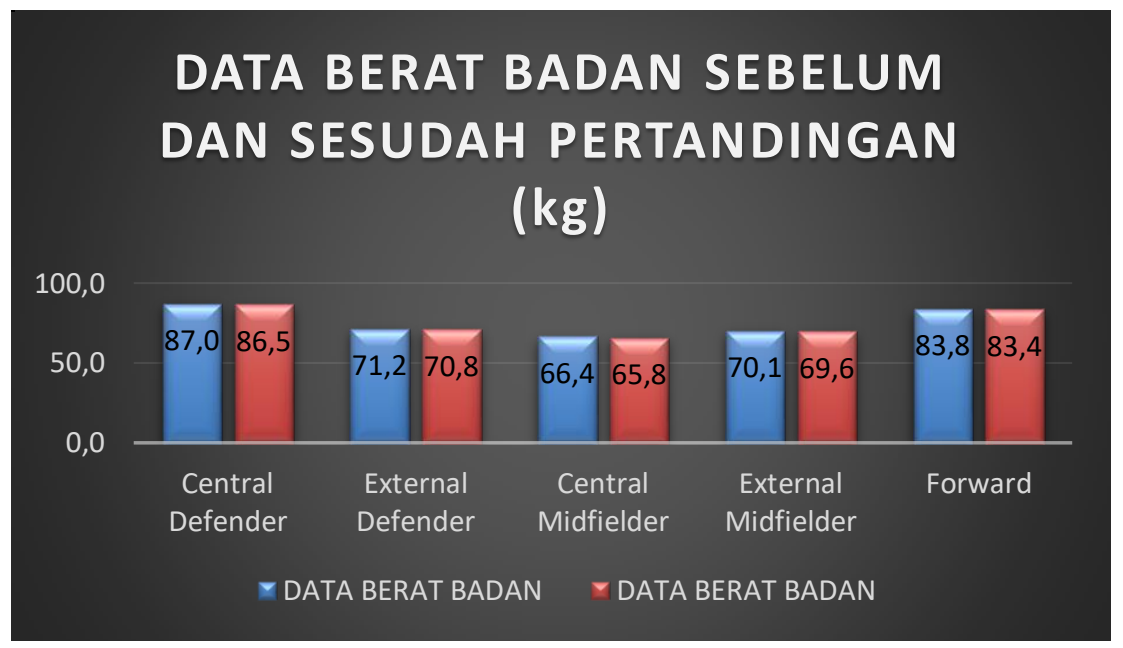

Data pada grafik 3 menunjukan hasil pengambilan data berat badan pemain BUFC pada pertandingan Piala Presiden 2019 melawan SPFC. Data tersebut dapat dilihat bahwa pemain Central Defender memiliki berat badan sebelum pertandingan $87.0 \mathrm{~kg}$ dan setelah pertandingan $86.5 \mathrm{~kg}$, External
Hal ini menunjukan perbedaan dari intensitas gerak pemain BUFC dalam pertandingan Piala Presiden melawan SPFC lebih di dominasi oleh pergerakan pemain Defender dibandingkan Forward dan Midfielder. Berbanding terbalik dengan capaian pemain semi profesional yang lebih dominan memiliki intensitas gerak paling banyak yaitu pemain Midfielder dibandingkan dengan Forward dan Defender. Dengan demikian data yang diperoleh menjadikan sebagai temuan baru dari penelitian sebelumnya mengenai capaian Heart Rate pemain selama pertandingan.

Data diatas hanya sebagai bahan pembanding dari data BUFC pada pertandingan. Selanjutnya, data yang ada menjadikan bahan evaluasi pelatih untuk merencanakan suatu progam latihan sesuai dengan kebutuhan pemain disetiap posisi berdasarkan kepada prinsip-prinsip latihan yaitu prinsip specificity dan individualisasi.
Defender $\mathrm{R}$ memiliki berat badan sebelum pertandingan $71.2 \mathrm{~kg}$ dan setelah pertandingan $70.8 \mathrm{~kg}$, Central Midfielder memiliki berat badan sebelum pertandingan $66.4 \mathrm{~kg}$ dan setelah pertandingan $65.8 \mathrm{~kg}$, External Midfielder memiliki berat badan sebelum pertandingan $70.1 \mathrm{~kg}$ dan setelah pertandingan 
$69.6 \mathrm{~kg}$, dan Forward memiliki berat badan pertandingan $83.4 \mathrm{~kg}$. sebelum pertandingan $83.8 \mathrm{~kg}$ dan setelah

Grafik 6. Presentasi Kehilangan Berat Badan

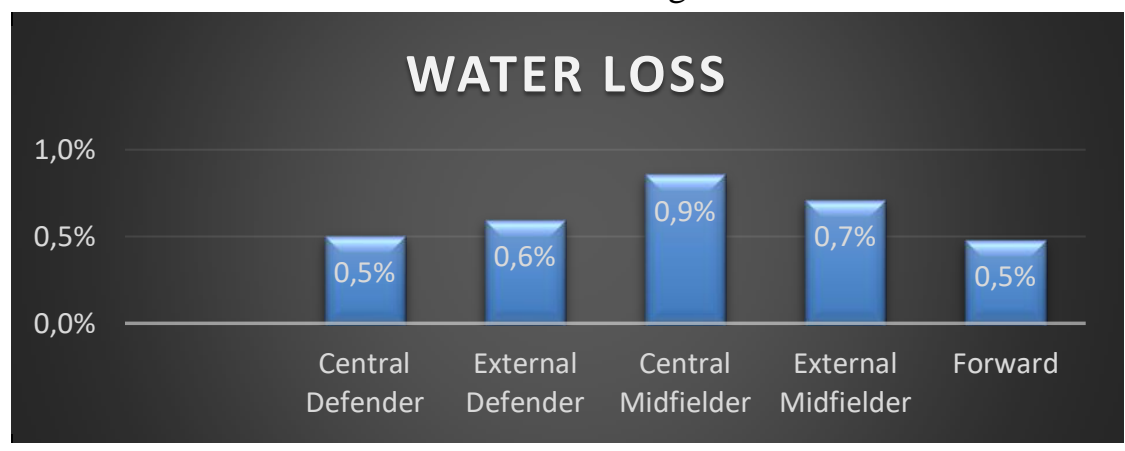

Data pada grafik 4 menunjukan persentasi penurunan berat badan pada pemain BUFC pada pertandingan Piala Presiden 2019 melawan SPFC. Dapat dilihat bahwa Central Midfielder mengalami penurunan berat badan sebesar $0.9 \%$, sedangkan Central Defender dan Forward mengalami penurunan berat badan yang sama sebesar $0.5 \%$ dari berat badan.

Data persentase kehilangan berat badan yang tercantum di atas merupakan salah satu acuan untuk mengetahui tingkat kehilangan cairan dalam tubuh. Seperti yang diketahui bahwa kehilangan cairan tubuh atau dehidrasi sebanyak $2 \%$ dari massa tubuh akan menyebabkan terganggunya kerja fisiologis dalam tubuh. Dalam pertandingan sepakbola rata-rata kehilangan cairan biasanya 1-2\% dari massa tubuh yang menunjukan bahwa dalam keadaan normal pemain dapat memacu diri pemain sendiri untuk menyelesaikan pertandingan dalam kondisi fisik yang wajar (Edwards \& Noakes, 2015).

Pada hasil penelitian ini belum adanya mengenai hasil yang menjelaskan mengenai persentase kehilangan cairan tubuh pemain sepakbola diberbagai posisi menjadikan suatu hal yang baru agar dijadikan bahan referensi bagi para praktisi sepakbola mengenai pentingnya asupan cairan. Dari hasil penelitian dapat dijelaskan bahwa kehilangan cairan tubuh pemain selama pertandingan belum menunjukan kearah dehidrasi yang berlebihan. Namun, asupan cairan bagi tubuh sangat penting supaya pemain tidak mengalami gangguan fungsi fisiologis yang berlebihan sehingga pemain akan tetap bias bermain dengan menunjukan performa yang baik selama pertandingan.

Hasil diatas memiliki persamaan dan perbedaan di berbagai posisi, hal ini menunjuka kinerja pemain selama pertandingan.

\section{SIMPULAN}

Berdasarkan hasil pengambilan data BUFC pada pertandingan Piala Presiden 2019 melawan SPFC dapat disimpulkan bahwa setiap posisi memiliki perbedaan nilai Distance Covered, Heart Rate, dan kehilangan cairan tubuh. Dari hasil penelitian terdapat 3 posisi pemain yang lebih dominan Distance Covered, Heart Rate, dan kehilangan cairan tubuh yaitu: External Defender, Central Midfielder, dan External Midfielder. Hasil ini menjadikan bahan acuan bagi pelatih dalam merancang suatu program latihan sesuai dengan kebutuhan pemain disetiap posisi berdasarkan kepada prinsip-prinsip latihan yaitu prinsip spesifik dan individualisasi.

\section{DAFTAR PUSTAKA}

Alexandre, D., Silva, C. D. Da, Hill-Haas, S., Wong, D. P., Natali, A. J., De Lima, J. R. P., .. Karim, C. (2012). Heart ratemonitoring in soccer: Interest and 
limits during competitive match play and training, practical application. Journal of Strength and Conditioning Research, 26(10), 2890-2906. https://doi.org/10.1519/JSC.0b013e3182 $429 \mathrm{ac} 7$

Ali, A., \& Farrally, M. (2007). rates during matches Recording soccer players $\hat{a} €^{\mathrm{TM}}$ heart rates during matches, (July 2013), $37-41$.

https://doi.org/10.1080/02640419108729 879

Andrzejewski, M., Chmura, J., Pluta, B., \& Konarski, J. M. (2015). Sprinting Activities and Distance Covered by Top Level Europa League Soccer Players. International Journal of Sports Science \& Coaching, 10(1), 39-50. https://doi.org/10.1260/17479541.10.1.39

Bangsbo, J., Mohr, M., Krustrup, P., \& Bangsbo, J. (2006). Physical and metabolic demands of training and match play in the elite soccer player Correspondence to :, 1-16.

Bojkowski, Ł., Eider, J., Śliwowski, R., \& Wieczorek, A. (2015). Analysis of the Longest Distances Run by the Best Soccer Players at the FIFA World Cup in Brazil in 2014. Central European Journal of Sport Sciences and Medicine, 11(3), 145-151. https://doi.org/10.18276/cej.2015.3-15

Boone, J., Vaeyens, R., Steyaert, A., Bossche, L. Vanden, \& Bourgois, J. (2012). Physical Fitness of Elite Belgian Soccer Player by Player, 26(8), 2051-2057.

Capranica, L., Tessitore, A., Guidetti, L., \& Figura, F. (2010). Heart rate and match analysis in pre-pubescent soccer players Heart rate and match analysis in pre- pubescent soccer players, (December 2012), 37-41.

Di Salvo, V., Baron, R., Tschan, H., Calderon Montero, F. ., Bachl, N., \& Pigozzi, F. (2007). Performance Characteristics According to Playing Position in Elite Soccer, (May 2014). https://doi.org/10.1055/s-2006-924294

Edwards, A. M., \& Noakes, T. D. (2015). Dehydration Cause of Fatigue or Sign of Pacing in Elite Soccer?, (February 2009).

Lyakh, V., Witkowski, Z., \& Litkowycz, R. (2016). Periodization in Team Sport Games - A Review of Current Knowledge and Modern Trends in Competitive Sports, 54(December), 173180. https://doi.org/10.1515/hukin-20160053

Phillips, S. M., Sykes, D., \& Gibson, N. (2014). Hydration Status and Fluid Balance of Elite European Youth Soccer Players during Consecutive Training Sessions, (December), 817-822.

Russell, M., Sparkes, W., Northeast, J., Cook, C. J., Bracken, R. M., \& Kilduff, L. P. (2016). Relationships between match activities and peak power output and Creatine Kinase responses to professional reserve team soccer matchplay. Human Movement Science, 45, 96101.

https://doi.org/10.1016/j.humov.2015.11. 011

Siegler, J. C., Mermier, C. M., Amorim, Fa. T., Lovell, R. J., McNaughton, L. R., \& Robergs, R. A. (2008). Hydration , Thermoregulation, and Performance Effect of Two Sport Drinks During Soccer Training Session, 1(33), 13941401. 
Siregar, N. S. (2016). Pengaruh Rehiddrasi Setelah Olahraga dengan Air Kelapa, 15, 12-20.

Taylor, P., Hencken, C., White, C., Hencken, C., \& White, C. (2006). European
Journal of Sport Science Anthropometric assessment of Premiership soccer players in relation to playing position to playing position, (September 2013), 37-41. https://doi.org/10.1080/17461390601012 553 